\title{
Evaluation of temperature sum models and timing of Quassia amara (Simaroubaceae) wood-chip extract to control apple sawfly (Hoplocampa testudinea Klug) in Sweden
}

\author{
P. Sjöberg • W. Swiergiel • D. Neupane • \\ E. Lennartsson - T. Thierfelder - M. Tasin • \\ B. Rämert
}

Received: 19 February 2014/Revised: 29 July 2014/ Accepted: 4 August 2014/Published online: 18 August 2014

(C) The Author(s) 2014. This article is published with open access at Springerlink.com

\begin{abstract}
Apple sawfly (Hoplocampa testudinea Klug) is a serious pest in European organic apple production. They hatch during a short period only, making correct timing of control measures crucial. Swedish organic growers have requested a strategy for optimal timing of the Quassia amara (Simaroubaceae) extract against the apple sawfly. The aim of this study was, therefore, to develop methods to predict the timing of $Q$. amara control in Sweden. A temperature sum model for timely placement of monitoring or mass-trapping sticky traps was validated for Swedish conditions. The average emergence of sawflies occurred at 169 degree days $(\mathrm{SD}=20)$ counted from March 15 (threshold temperature $4{ }^{\circ} \mathrm{C}$ ). The difference in emergence from existing first flight model of average and maximum 9 and 39 degree days ( 1 and 9 calendar days) was found acceptable. Accumulated oviposition of $85 \%$ at full bloom (BBCH 65) suggests that mass trapping and monitoring could stop at this time. This is supported by a tendency of decreased trap catches during that period. Three application times for $Q$. amara were compared: (A) at petal fall (BBCH 67), (B) at a date calculated using female trap catch numbers and temperature sums, and $(\mathrm{C})$ prior to peak egg
\end{abstract}

P. Sjöberg and W. Swiergiel have contributed equally to the study.

Communicated by C. Cutler.

P. Sjöberg · W. Swiergiel ( $₫)$ - D. Neupane · E. Lennartsson ·

M. Tasin · B. Rämert

Department of Plant Protection Biology, Swedish University of Agricultural Sciences, P.O. Box 102, SE-230 53 Alnarp, Sweden

e-mail: weronika.swiergiel@slu.se

T. Thierfelder

Department of Energy and Technology, Swedish University of Agricultural Sciences, P.O. Box 7032, SE-750 07 Uppsala, Sweden hatch observed in the field. All treatments resulted in significantly lower percentage of damaged apples compared to the unsprayed control, with significantly less damage $(1.3 \%)$ in plots treated according to method (B). The results provide information on adult phenology and methods that could be used to determine timing of mass trapping and insecticide application against the apple sawfly.

Keywords IPM · Organic · Forecasting · Monitoring

\section{Key message}

- Forecasting methods for pesticide application against the apple sawfly were validated for Swedish conditions by application of the bio-pesticide Quassia amara.

- Timing of intervention, based on a date calculated using female trap catch and temperature sums, achieved significantly less damage than models based on phenological plant stage or on observed peak of egg hatch.

- By applying $Q$. amara in accordance with a temperature model, a low impact strategy for the control of the sawfly in orchards is proposed.

\section{Introduction}

Apple sawfly (Hoplocampa testudinea Klug; Hymenoptera: Tenthredinidae) is an important univoltine pest of apple in Europe and North America (Pyenson 1943; Vincent and Mailloux 1988; Cross et al. 1999; Velbinger 1939). The sawfly hibernates in the soil as pre-pupae and emerges in the flowering period of early and moderately early apple varieties (Graf et al. 2001; Ciglar and Baric 
2002; Miles 1932). Accordingly, there is a link between the reproductive period of the apple sawfly and the phenological flowering stages of apple trees, which can be described by the biologische bundesanstalt, bundessortenamt und chemische industrie (BBCH) scale (Meier et al. 1994) and used to time control measures against the pest. Without pesticide application or parasitism, sawfly populations in the Netherlands can double every year (Zijp and Blommers 2002b). The damage caused by sawfly larvae comprises characteristic primary damage with winding tunnels under the fruitlet skin caused by 1 st and 2nd instar larvae and secondary damage caused by older instars with direct entrance to the ovary and no winding scars (Miles 1932; Dicker and Briggs 1953). Apple sawfly control in Swedish conventional orchards relies on the use of nonselective synthetic insecticides (Manduric 2013), while control in European organic orchards commonly has relied on the use of a commercial or homemade extract from the shrub Quassia amara (Simaroubaceae) (Ascard and Juhlin 2011; Trapman pers. com. 2012). The short persistence of $Q$. amara extract avoids a negative effect on the later emerging apple sawfly parasitoid Lathrolestes ensator (Zijp and Blommers 2002a, b). The extract is sprayed after flowering to eradicate neonate larvae of the sawfly. Quassinoids such as quassin and neoquassin are reported to be the active toxins in $Q$. amara extract (Kienzle et al. 2006; Villalobos-Soto et al. 1999). The commercially recommended timing of $Q$. amara application, at petal fall, is estimated to coincide with egg hatch. Monitoring of adult sawfly emergence, estimation of population density, and mass trapping are possible using white sticky traps (Owens and Prokopy 1978; Wildbolz and Staub 1986; Graf et al. 1996a). The apple sawfly is visually attracted by the nonUV reflecting white color of the trap (Owens and Prokopy 1978). A majority of sawflies trapped are considered to have emerged from soil hibernation within the preceding $24 \mathrm{~h}$ (Graf et al. 1996b). The common recommendation is to place traps 10 days before bloom, since if they are installed too early they attract other insects and may lose their attractiveness (Graf et al. 1996c).

Monitoring with traps only provides an indication of the adult activity, without containing any information regarding the development of eggs and/or larvae. However, exact timing of spraying is an essential prerequisite for satisfactory control of apple sawfly (Höhn et al. 1993; Kienzle et al. 2002). As a consequence, several phenology-driven models based on soil and air temperature have been developed to predict the spring emergence of the adult sawflies, the time of mating, and the period of egg development (Graf et al. 1996a; Zijp and Blommers 1997; Graf et al. 2001, 2002). An early model employed soil temperature to estimate the emergence of adults (Graf et al. 1996a), but air temperature is cheaper and easier to measure and more commonly used by advisory services and growers for the management of other apple pest species (Jones et al. 2010; Roubal and Rouzet 2003; Agnello and Reissig 2010). A study by Zijp and Blommers (1997) showed that air temperature resulted in approximately the same precision as soil temperature. A better estimate of optimal insecticide timing can be obtained when the information from trap catches is combined with weather data and with empirically derived temperature sum for egg development (Graf et al. 2001, 2002). Soil texture has also been shown to influence the timing of sawfly emergence (Graf et al. 1996a) and this could theoretically alter the relationship between air and soil temperature, and hence the appropriateness of using air temperature at different locations. Furthermore, Graf et al. (1996b) found that the relationship between temperature and developmental stage of sawfly populations from different European regions differed significantly, even when the thermal threshold was similar. According to these authors, in order to expand the validity of the model, the temperature dependence of development has to be quantified for different populations.

The aims of the present study were to determine whether (i) the first trap catch of apple sawfly in Sweden could be predicted by the air-based temperature sum model of (Zijp and Blommers 1997) and used to indicate optimal timing of trap placement for monitoring or mass trapping; (ii) trap catches of sawflies decrease because of visual competition from the actual flowers during bloom; (iii) apple tree phenology would co-vary with observed egg and larval stages; and (iv) the efficacy of $Q$. amara treatment differs depending on time of application, e.g., at petal fall, or as recommended based on female trap catches and existing temperature sums for adult lifespan to egg development (Graf et al. 2001, 2002) or at observed egg hatch under Swedish conditions. Such information may be important when optimizing apple sawfly control measures within an integrated pest management approach.

\section{Material and methods}

\section{Evaluation of first trap catch model}

Populations of apple sawfly were monitored during 2011-2013 in seven orchards (1-7) in southern Sweden (Table 1). The orchards were located at least $20 \mathrm{~km}$ from each other and five were managed organically, while two were under integrated production (IP). During field seasons, weather data (air temperature, relative humidity, and rain) were recorded at each orchard using Vantage Pro weather stations (Davis Instruments, San Francisco, CA, USA). Rebell bianco sticky traps (Andermatt Biocontrol AG, Grossdietwil, Switzerland) were used to record flight 
Table 1 Swedish apple orchards used to evaluate apple sawfly (Hoplocampa testudinea) phenology and/or management with Quassia amara extract (2011-2013)

\begin{tabular}{|c|c|c|c|c|c|c|}
\hline Orchard & $\begin{array}{l}\text { GPS coordinates } \\
\text { (WGS84) }\end{array}$ & $\begin{array}{l}\text { Size } \\
\text { (ha) }\end{array}$ & $\begin{array}{l}\text { Production } \\
\text { system }\end{array}$ & Trap observation & Year & Experiment conducted \\
\hline 1 & $\mathrm{~N} 55^{\circ} 43.229^{\prime}, \mathrm{E} 14^{\circ}$ & 0.25 & IP & Every day & $\begin{array}{l}2011 \\
2012 \\
2013\end{array}$ & $\begin{array}{l}\text { Trap observation }+Q \text {. amara } \\
\text { Trap observation }+Q \text {. amara } \\
\text { Trap observation }+Q \text {. amara }\end{array}$ \\
\hline 2 & $\mathrm{~N} 56^{\circ} 2.993^{\prime}, \mathrm{E} 12^{\circ}$ & 0.9 & Organic & Every day & $\begin{array}{l}2011 \\
2012 \\
2013\end{array}$ & $\begin{array}{l}\text { Trap observation }+Q \text {. amara } \\
\text { Trap observation }+Q \text {. amara } \\
\text { Trap observation }+Q \text {. amara }\end{array}$ \\
\hline 3 & $\mathrm{~N} 56^{\circ} 27.251^{\prime}$, E $12^{\circ}$ & 10 & Organic & Every day & 2013 & Trap observation $+Q$. amara \\
\hline 4 & $\mathrm{~N} 55^{\circ} 44.556^{\prime}$, E $13^{\circ}$ & 2 & Organic & Twice per week & $\begin{array}{l}2011 \\
2012 \\
2013\end{array}$ & $\begin{array}{l}\text { Trap observation } \\
\text { Trap observation } \\
\text { Trap observation }\end{array}$ \\
\hline 5 & $\mathrm{~N} 55^{\circ} 36.534^{\prime}$, E $14^{\circ}$ & 1.5 & Organic & Twice per week & $\begin{array}{l}2011 \\
2012 \\
2013\end{array}$ & $\begin{array}{l}\text { Trap observation } \\
\text { Trap observation } \\
\text { Trap observation }\end{array}$ \\
\hline 6 & $\mathrm{~N} 55^{\circ} 39.523^{\prime}$, E $14^{\circ}$ & 12 & Organic & Twice per week & $\begin{array}{l}2012 \\
2013\end{array}$ & $\begin{array}{l}\text { Trap observation } \\
\text { Trap observation }\end{array}$ \\
\hline 7 & $\mathrm{~N} 56^{\circ} 6.886^{\prime}, \mathrm{E} 14^{\circ}$ & 17 & IP & Twice per week & 2012 & Trap observation \\
\hline
\end{tabular}

pattern and monitor the emergence of adults. Six traps were placed in each orchard, at random positions approximately $1.5 \mathrm{~m}$ above the ground and at a minimum distance of $30 \mathrm{~m}$ from each other except in orchards one and three (minimum $10 \mathrm{~m}$ distance) due to smaller orchard size. Early flowering cultivars in Swedish organic orchards were used (Amorosa, Collina, Discovery, Holsteiner Cox, Nanna, Rubinola, Santana). The traps were placed in the orchards at the end of April and removed after the end of flight each year. They were replaced at each recording occasion. Trap catches at orchards one, two, and three were recorded every day due to the precision in timing required by the $Q$. amara trial. In the remaining orchards, trap catches were recorded twice a week to record the pattern of population emergence (Table 1). At each location, observed adult emergence was compared with the associated predicted emergence based on the temperature sum construct proposed by Zijp and Blommers (1997) (Table 2). The average temperature sum and standard deviation for all years and orchards were compared to the Zijp and Blommers (1997) reference value of $177 \pm 10$ degree days.

\section{Relationship between trap catches and flowering stages}

Observed adult emergence was compared locally with apple tree phenology according to the $\mathrm{BBCH}$ scale (Meier et al. 1994).
Relationship between tree phenology (BBCH), egg, and larval development

During 2013, egg and larval developments were compared with temperature sum forecasts from air temperature, trap catches, and apple tree phenology. The egg and larval observations were made every day and due to logistical and time restrictions the study was limited to orchards two and three. A minimum of 20 apples with either ovipositional scar, superficial tunneling or radial entrance holes were randomly collected from trees throughout each orchard. Their development stage was recorded by microscopy. Six egg stages, dsA-dsF, were determined from schematic drawings (Kuenen and Vrie 1951) and larval stage by measurement of head capsule size (Miles 1932). The temperature sum was obtained by entering recorded maximum and minimum daily air temperature data for each orchard into an Excel spreadsheet, and use pre-established formulae to calculate degree days (Snyder 1985).

\section{Application timing and efficacy of Quassia amara}

A field trial with wood-chip extract of $Q$. amara was conducted in 2011 and 2012 at orchard one. The aim was to measure the efficacy of $Q$. amara, applied according to the common commercial practice of spraying at petal-fall (BBCH stage 67-69) (Treatment A), as compared with an unsprayed control. In 2013, the experiment was expanded 
to orchards two and three and included a study on the efficacy of $Q$. amara timed according to temperature sums (Treatment B). Temperature sums for adult lifespan, oviposition, and egg development proposed by Graf et al. (2001, 2002) were calculated, as described above, from daily recorded accumulated female trap catches and local weather data. The resulting accumulated curves indicated the theoretical egg hatch peak at which $Q$. amara application was performed. In a third treatment (Treatment C), based on field observations of egg development stages, $Q$. amara was sprayed when the majority of the eggs reached the final development stage $\mathrm{F}(\mathrm{dsF})$ before hatching. Treatment $\mathrm{C}$ was excluded from orchard one due to the low number of eggs found. Summary of treatments:

A: application at petal fall (BBCH stage 67-69 - year 2011-2013), orchards 1-3

B: application according to accumulated trapcatches + temperature sums (year 2013), orchards 1-3

$\mathrm{C}$ : application at final egg stage $\mathrm{F}$, just prior to observed peak larvae hatching (year 2013), orchards 2-3

D: Control: unsprayed (year 2011-2013), orchards 1-3 Quassia extract applications were made according to a randomized complete block design, with four blocks per orchard. Every block contained all three treatments and the untreated control. The blocks contained 40 trees in a row and a group of 10 trees were randomly assigned to each treatment. A buffer zone between treatments was composed of one tree on each side. The effect of $Q$. amara was measured by counting the number of undamaged and damaged fruits on 3-5 randomly chosen trees in each block and treatment approximately 2 weeks after the first application and with the same trees sampled again after two additional weeks (damage check occasion 1 and 2, respectively, see Table 3 and Fig. 2). Fruit damage included primary and secondary damage caused by the apple sawfly (Dicker and Briggs 1953).

Wood chips were prepared according to the Swedish board of Agriculture recommendations of $12 \mathrm{~kg} / \mathrm{ha}$, with the chips infused in warm tap water $\left(60{ }^{\circ} \mathrm{C}\right)$ for a period of $24 \mathrm{~h}$ and then filtered (Ascard and Juhlin 2011). The filtered extract was mixed with water and Zence 40 (potassium oleate) as a wetting agent (1\%) and application was carried out in late evening, using a back-pack sprayer (Solo Accu Power 416, Solo Kleinmotoren GmbH, Sindelfingen, Germany) at a field rate of $400 \mathrm{~L} / \mathrm{ha}$. High pressure liquid chromatography (HPLC) was used to determine the quassin content in the different wood chip batches in the experiment. The field dose of approximately $12 \mathrm{~kg} / \mathrm{ha}$ of $Q$. amara was adjusted each year to correspond to $13.3 \mathrm{mg}$ quassin/L. For the HPLC, an aliquot of $500 \mu \mathrm{L}$ of the aqueous wood-chips extract was filtered in a $0.2 \mu \mathrm{m}$ centrifugation filtration unit and centrifuged for $2 \mathrm{~min}$ $(1,300 \mathrm{rpm})$ at room temperature. One hundred $\mu \mathrm{L}$ of the sample was injected into the HPLC. Each sample was injected twice. A Waters HPLC system consisting of two pumps and one automatic gradient controller was used. The detector was an Agilent 1,200 diode array detector working at $254 \mathrm{~nm}$. The sample was introduced to the column via a Rheodyne injector fitted with a $100 \mu \mathrm{L}$ loop. The HPLCstationary phase consisted of a $4 \mu \mathrm{m} \mathrm{C} 18$ column (Waters, $3.9 \times 150 \mathrm{~mm})$ and the mobile phase was Milli-Q water with $1 \%(\mathrm{w} / \mathrm{w})$ acetic acid (pump A) and methanol with $1 \%(w / w)$ acetic acid (pump B). Gradient separation was performed at a flow rate of $1.0 \mathrm{~mL} / \mathrm{min}$. The initial mobile phase ratio was $80 \% \mathrm{~A}$ and $20 \% \mathrm{~B}$. A linear gradient to $40 \% \mathrm{~A}$ and $60 \% \mathrm{~B}$ was operated from 0 to $20 \mathrm{~min}$ and quassin had a retention time of ca $16 \mathrm{~min}$. The data were acquired and processed with Agilent Chemstation software. Pure quassin was used as standard for preparing a calibration curve with peak area versus known amount of quassin. Pure quassin was isolated from $Q$. amara wood chips. One $\mathrm{kg}$ of wood chips was extracted for $24 \mathrm{~h}$ in $2 \mathrm{~L}$ of Milli-Q water. The extract was filtered and the water adjusted to $\mathrm{pH} 3.7$ with $\mathrm{HCl}$. The extract was partitioned three times with equal volumes of EtOAc. The EtOAc fractions were combined and stored at $-20{ }^{\circ} \mathrm{C}$ over night. Water was removed from the EtOAc by filtering off the ice. The EtOAc was evaporated to dryness in a Rotavapor at $35^{\circ} \mathrm{C}$. The sample was dissolved in $1 \mathrm{~mL}$ water and injected in $100-\mu \mathrm{L}$ aliquots into the HPLC and fractions corresponding to quassin were collected. The solvent was evaporated to dryness in a SpeedVac concentrator at $35{ }^{\circ} \mathrm{C}$ yielding crystalline quassin of high purity. A known amount of crystalline quassin was dissolved in $80 \%$ water and $20 \% \mathrm{MeOH}$ and further diluted to prepare a standard curve showing amount of quassin versus UV absorption at $254 \mathrm{~nm}$.

The chemical identity of the peak corresponding to putative quassin was established by ultra-high performance liquid chromatography (UHPLC)-electrospray ionization (ESI)-linear trap quadropole (LTQ) orbitrap mass spectrometry (MS). This method was used to find out mass to charge ratio of the particles for determining the elemental composition of quassin. Comparison was made with library data of fragmentation of quassin. Tandem mass spectra were used to further verify the chemical structure of the compound corresponding to putative quassin (Odén, P. C. et al., ms in preparation).

\section{Data analysis}

The basic statistical assumption made when sawfly populations were studied across orchards and years was that populations are orchard specific, meaning that sawflies do not fly and mate across orchards (our study orchards were situated at least $20 \mathrm{~km}$ apart). The phenological characteristics of 
individual populations are therefore longitudinally transferred along the time-line within orchards, from 1 year to another. The statistical consequence of this defines the population concept; phenological covariance carries on from one generation to another, causing phenological observations to be inherited within, but not across, orchards. With such non-symmetric covariance structures being typical in longitudinal experimental designs, they are typically solved with a mixed linear model (Fitzmaurice et al. 2010). In statistical terms, the objective of the $Q$. amara trial was to determine whether treatments $\mathrm{A}-\mathrm{C}$ had an effect on the relative proportions of damaged fruit as compared with the untreated control. In addition, it was investigated whether the effects of treatment varied temporally from one damage check occasion to another. This is basically an ANOVA setup with two fixed nominal factors Treatment and Occasion, where the effect of Treatment within the levels of Occasion the two levels of first and second damage check, where the interactive factor may be interpreted as addressing the temporal stability (homogeneity) of eventual treatment effects. In the present design, the first damage check occasion serves as a baseline for comparison with the second damage check (with null hypothesis that they do not differ), which eliminates the cumulative effect where the fruit damaged at occasion 1 also is counted at occasion 2. Furthermore, the basic ANOVA setup assumes normality and homoscedasticity, whereof neither was met. Instead, the response (damaged fruit) was binomial, with each apple either accepted or rejected. When this binomial process was summarized and compared with the total amount of fruit, a proportion in the interval $\mathrm{p}=[0,1]$ was theoretically possible. However, when this interval was logit-transformed onto the interval $[-\infty,+\infty]$, the resulting transformation could be considered approximately normal. The basic empirical assumption of sawfly phenology being inherited within orchards also contradicts the normality assumption of independent observations. This problem was solved with a mixed linear model, where the nominal factor Orchard_id was considered as being random, which introduced the concept of covariance to all observations grouped per orchard. Since the within-orchard design encompasses all possible sources of within-orchard covariance, effects such as orchard-specific climate, weather, management strategy, and autocorrelation characteristics were automatically captured with Orchard_id. When the above assumptions were combined into one inferential design, a mixed ANOVA was obtained where the response was a logit transformation of the proportions of damaged fruits.

The above mixed design was also applied to the relation between trap catches and flowering stages. In this case, a Box-Cox transformation of primary trap-catch counts was compared with the flowering stages BBCH 59, 60, 65, 67, and 69 (pre-bloom, incipient bloom, full bloom, incipient post-bloom, and full post-bloom, respectively). BBCH was considered to be an ordinal factor, with its effect on trapcatches estimated and plotted for visual interpretation. All mixed equations were solved with restricted maximumlikelihood algorithms, implemented in the software package STATISTICA ver. 12 (Statsoft 2014).

\section{Results}

Evaluation of first trap catch model

Trap catches of apple sawfly were observed from the beginning of May to mid-June. On average, first emergence of the sawfly occurred at $169 \pm 20$ degree days from March 15 , compared with $177 \pm 10$ degree days as predicted by Zijp and Blommers (1997). The average difference between observed and predicted emergence was one calendar day or 9 degree days and the maximum difference was nine calendar days or 39 degree days (Table 2). However, $5 \%$ of accumulated flight occurred on average 3 days after predicted first flight and never before April 30 in the 3 years of this study (Table 2). The average number of calendar days from predicted first flight to full bloom was 14 (Table 2).

\section{Relationship between trap catches and flowering stages}

Trap catches in all orchards had a strong tendency $(F(3$, $155)=2.574, p<0.056)$ to decrease at full flowering (BBCH 65), and increase again after petal fall (BBCH 69).

Relationship between tree phenology (BBCH), egg, and larval development

The first eggs were found 5-8 days after female sawflies emerged (Fig. 1). Prior to BBCH 65, approximately $85 \%$ of all eggs were deposited but only $60 \%$ of the total amount of female sawfly trap catches were recorded (Fig. 1). The period between first and last egg found for each respective egg stage lasted approximately 10 days, with a total egg stage period (dsA-dsF) of approximately 3 weeks (Fig. 1). The first sawfly larvae observed on apples appeared approximately 2 weeks after first appearance of the eggs (Fig. 1). The larval stage lasted approximately 30 days, with the period between first and last larva found for each larval stage lasting 10-15 days (Fig. 1). The average time from female flight to larval stage five was 32 days.

Application timing and efficacy of Quassia amara

At the second damage check occasion, the lowest level of accumulated damage $(1.3 \%)$ was obtained with treatment (trt) B, where $Q$. amara extract was applied according to 
Table 2 First trap catch and $5 \%$ accumulated catch (acc.) of apple sawfly (Hoplocampa testudinea) (2011-2013) in seven Swedish apple orchards and the difference in degree days (DD) and calendar days as compared with the temperature sum of Zijp and Blommers (1997). Averages and SD comprise all years and orchards

\begin{tabular}{lllllll}
\hline Orchard & $\begin{array}{l}\text { First catch } \\
(\mathrm{DD})\end{array}$ & $\begin{array}{l}\text { First } \\
\text { catch (date) }\end{array}$ & Diff. ${ }^{*}(\mathrm{DD})$ & $\begin{array}{l}\text { Diff. } \\
\text { (days) }\end{array}$ & $\begin{array}{l}5 \% \text { acc. } \\
\text { catch (DD) }\end{array}$ & $\begin{array}{l}5 \% \text { acc. } \\
\text { catch (date) }\end{array}$ \\
\hline 1 & 195 & $2011-05-01$ & 18 & 3 & 206 & $2011-05-06$ \\
& 175 & $2012-05-07$ & -2 & 0 & 180 & $2012-05-08$ \\
& 153 & $2013-05-09$ & -24 & -3 & 163 & $2013-05-10$ \\
2 & 190 & $2011-04-30$ & 13 & 2 & 195 & $2011-05-02$ \\
& 160 & $2012-05-03$ & -17 & -4 & 176 & $2012-05-07$ \\
& 149 & $2013-05-09$ & -28 & -3 & 167 & $2013-05-11$ \\
3 & 151 & $2013-05-09$ & -26 & -3 & 182 & $2013-05-13$ \\
4 & 209 & $2011-05-09$ & 32 & 9 & 209 & $2011-05-09$ \\
& 174 & $2012-05-10$ & -3 & 0 & 174 & $2012-05-17$ \\
& 166 & $2013-05-13$ & -11 & -2 & 166 & $2013-05-16$ \\
5 & 175 & $2011-05-06$ & -2 & -0 & 175 & $2011-05-06$ \\
& 138 & $2012-05-03$ & -39 & -8 & 152 & $2012-05-07$ \\
& 143 & $2013-05-13$ & -34 & -4 & 164 & $2013-05-16$ \\
6 & 189 & $2012-05-10$ & 12 & 1 & 225 & $2012-05-18$ \\
& 176 & $2013-05-13$ & -1 & 0 & 204 & $2013-05-17$ \\
7 & 153 & $2012-05-02$ & -24 & -5 & 187 & $2012-05-09$ \\
& $169(\mathrm{SD}=20)$ & & $-9(\mathrm{SD}=20)$ & $-1(\mathrm{SD}=3)$ & $183(\mathrm{SD}=20)$ & \\
\hline
\end{tabular}

combined female trap catch number and temperature sum (Graf et al. 2001, 2002) (Table 3). In all treatments, the total accumulated amount of damaged fruit was below $3.3 \%$ and significantly lower than the $8.1 \%$ damage in the control $($ Control-trt A, $F(1,283)=16.99, p<0.001$; Control-trt B, $F(1,284)=124.05, \quad p<0.001 ;$ Control-trt C, $F(1$, $243)=49.58, p<0.001$, Table 3$)$. Treatment $\mathrm{B}$ also showed lower damage levels than both Treatment A $(F(1$, $283)=16.99, \quad p<0.001)$ and $\mathrm{C} \quad(F(1,195)=11.34$, $p<0.001$ ) (Table 3 ), while the latter two did not differ significantly $(F(1,243)=0.75, p<0.388)$ (Table 3$)$. Treatment B showed a significant interaction with the control $(F(1$, $282)=5.46, p<0.02$, Fig. 2), which had increased damage levels at the second damage check. It did, however, not differ significantly from application at petal-fall (Treatment $\mathrm{A} ; F(1$, $282)=3.44, p<0.065)$ or at egg hatch (Treatment $\mathrm{C} ; F(1$, $194)=2.49, p<0.116$ ) (Fig. 2), even though an increase in the mean damage was also observed for these treatments. With a maximum-likelihood algorithm used to estimate the effects of treatment, the latter two probability values may be interpreted as rather strong tendencies.

\section{Discussion and Conclusion}

Evaluation of first trap catch model

After hibernating in the soil, the apple sawfly emerges in spring at a time primarily depending on soil/air temperature (Graf et al. 1996a, b; Zijp and Blommers 1997). Using the temperature sum construct proposed by (Zijp and
Blommers 1997), we were able to estimate the timing of sawfly emergence with an average error of 1 day early and a maximum error of 9 days early. This relatively large deviation between studies may be explained by differences in population biology (Graf et al. 1996b) and regional differences as compared with the single Netherland field site used by Zijp and Blommers (1997). This deviation is acceptable since catching the first emerging individuals is not crucial for the purpose of mass trapping and monitoring peak flight. With the exception of one orchard (Table 2), five percent of accumulated flight occurred at average 3 days after the predicted first flight. Hence, to minimize the time during which traps are exposed and clogged with other insects, traps for monitoring or mass trapping could be placed according to Zijp and Blommers (1997) if the recommended safety margin of 157 degree days is used. First trap-catch occurred at average 14 days before full bloom (BBCH 65) and never before April 30. If temperature sums are not accessible then April 30 may be a simpler estimation for trap placement than the commonly recommended 10 days prior to bloom.

Relation between trap catches and flowering stages

At several combinations of sites and years, a double trap-catch peak was observed. The strong tendency of decreasing adult densities observed between peaks occurred during full bloom. Since white sticky traps are designed for visual attraction (Wildbolz and Staub 1986), we interpret the trap catch decrease as being caused by competition from apple blossoms, as previously reported by (Haalboom 
Fig. 1 Apple sawfly (Hoplocampa testudinea) phenology on apple trees (BBCH scale as vertical lines) based on accumulated female trap captures (a), egg development (b), and larval development (c) (Sweden, 2013)

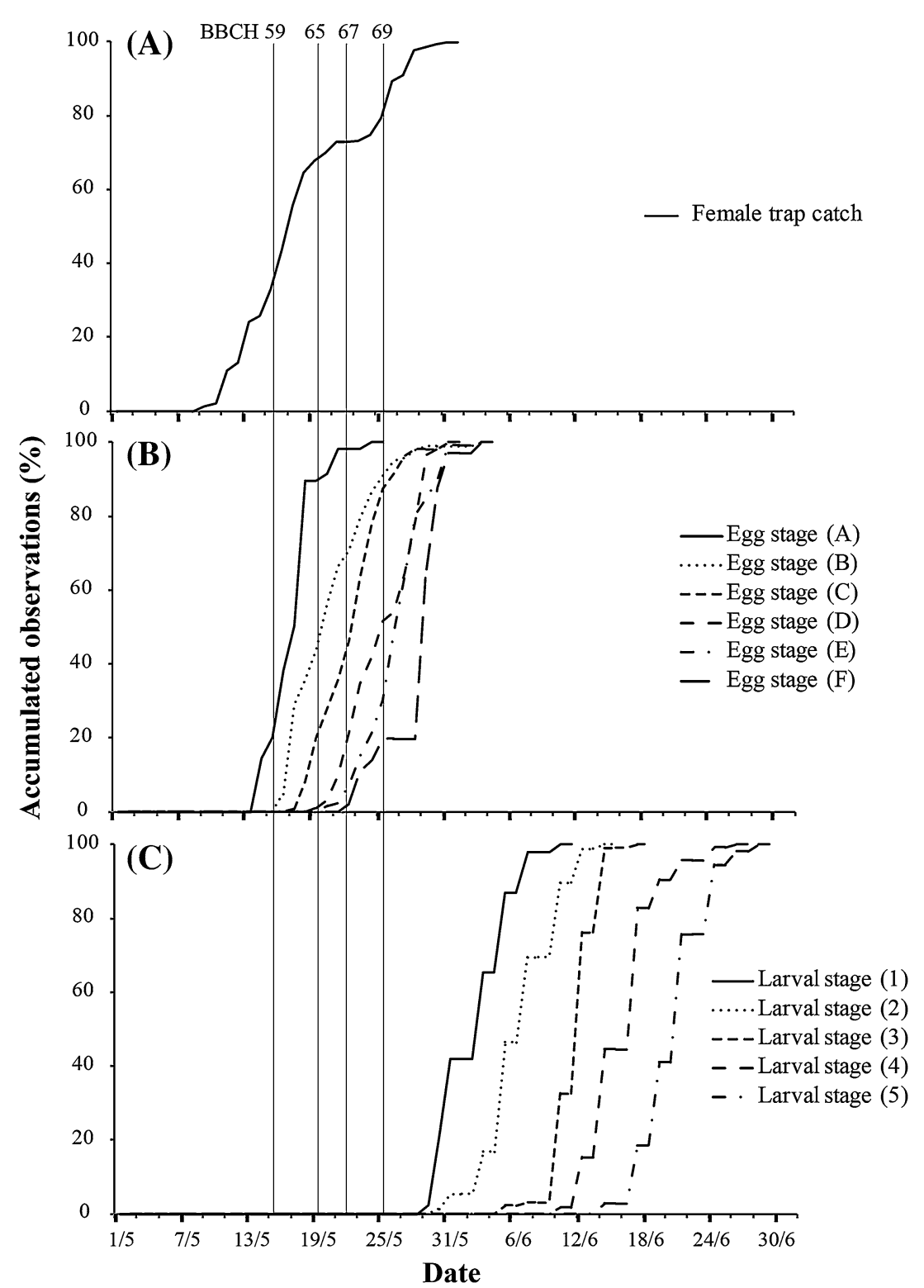

1983). This introduces an important bias to sawfly trap catches, where the seemingly interrupted flight curve probably reflects consistent adult activity.

Relation between tree phenology $(\mathrm{BBCH})$, egg, and larval development

Chaboussou (1961) observed that sawflies predominantly lay their eggs at BBCH 60-64 (Meier et al. 1994). This was confirmed to some extent in the present study, where more than $85 \%$ of eggs were found prior to full bloom (BBCH 65). However, our observations regarding trapped adult females contradicted this, with only $60 \%$ caught prior to full bloom (BBCH 65). This indicates that trap catches are not representative of egg deposition after BBCH 64. This inconsistency might explain the problems with finding a significant correlation between total trap-catch and fruit damage reported in previous studies (Graf et al. 1996c; Wildbolz and Staub 1986; Coli et al. 1985). In our orchards, the first sawfly larva was observed approximately 14 days after the first trap catch, which confirms the findings by Miles (1932).

Additionally, our observations indicate that the average time from peak flight to the final larval stage is 32 calendar days. This information could be used to calculate the timing of entomopathogenic fungi application. Previous studies have shown that entomopathogenic soil fungi (Jaworska 1992) and nematodes (Vincent and Bélair 1992) can contribute to decreasing sawfly populations. Therefore, in a future integrated approach, commercially available products of entomopathogenic fungi and/or nematodes could be applied just before sawfly larvae enter the soil. 

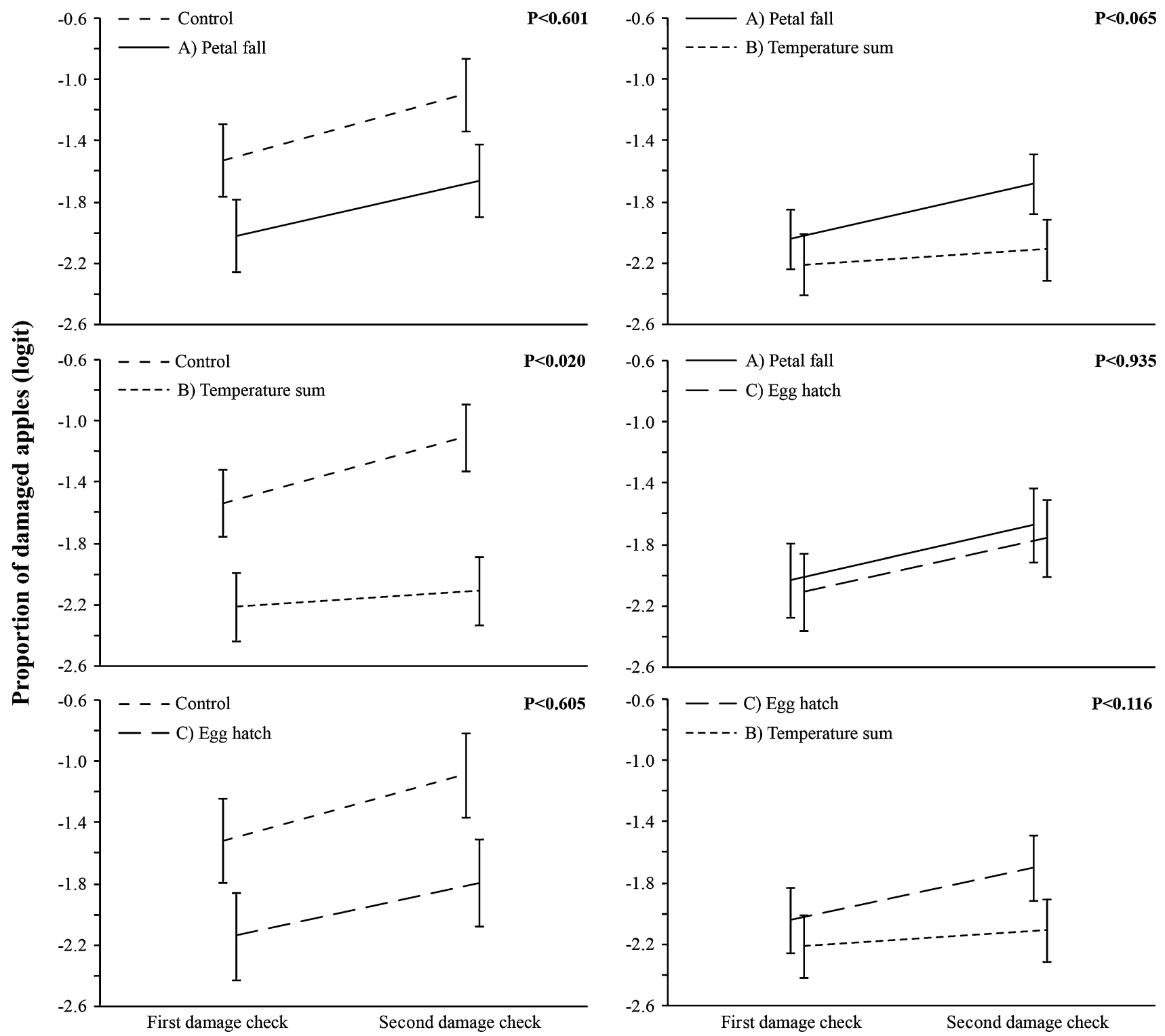

\section{Damage check occasion}

Fig. 2 Apple sawfly (Hoplocampa testudinea) damage ( $\pm 95 \% \mathrm{CI}$ ) in Swedish apple orchards (mixed model ANOVA with logit proportion pairwise interactions) with no treatment (control) or

\section{Application timing and efficacy of Quassia amara}

Based on the above findings, we suggest that unless the aim is mass trapping, white sticky traps should be used primarily to measure the trap-catch peak of female sawflies prior to bloom, in order to help forecast the correct timing of $Q$. amara application. This suggestion is based on our Q. amara experiments, where the best effect ( $1.3 \%$ fruit damage) was achieved with timing calculated as a combination of observed trap-catch peak of pre-bloom adult females and the temperature sums construct (Graf et al. 2001, 2002). following sprays of Quassia amara extract according to timings of petal-fall (a), a female sawfly trap capture temperature sum model (b), and egg hatch (c)

All three $Q$. amara application timings decreased the amount of damaged fruit as compared with the unsprayed control. The petal-fall treatment (A) was applied approximately 3 days earlier than the temperature sum treatment (B), i.e., a few days before the first larvae were found and while a majority of eggs were still not in the last stage. The egg-hatch treatment (C) was applied approximately 3 days after the temperature sum treatment, when the majority of the eggs had reached their final developmental stage. However, due to the difficulty in exact identification of this stage, a number of eggs could have hatched rather rapidly within the following hours and the corresponding neonate 
Table 3 Apple sawfly (Hoplocampa testudinea) damage in Swedish apple orchards following sprays of Quassia amara extract according to timings of petal-fall (a), a female sawfly trap capture temperature

\begin{tabular}{lllllll}
\hline Treatment & Year & Orchard & Application dates & First damage check & Second damage check & Average damage* $(\%)$ \\
\hline A & 2011 & 1 & $2011-05-19$ & $2011-05-30$ & $2011-06-15$ & $2.7 \mathrm{a}$ \\
& 2012 & 1 & $2012-05-24$ & $2012-06-07$ & $2012-06-20$ & $2013-06-19$ \\
& 2013 & 1 & $2013-05-23$ & $2013-06-06$ & $2013-06.19$ & $2013-06-19$ \\
& 2013 & 2 & $2013-05-23$ & $2013-06-06$ & $2013-06-19$ & $1.3 \mathrm{~b}$ \\
B & 2013 & 3 & $2013-05-23$ & $2013-06-06$ & $2013-06-19$ & $2013-06-19$ \\
& 2013 & 1 & $2013-05-25$ & $2013-06-06$ & $2013-06-19$ & $3.3 \mathrm{a}$ \\
C & 2013 & 2 & $2013-05-26$ & $2013-06-06$ & $2013-06-19$ & \\
\end{tabular}

sum model (b), or egg hatch (c). Percent damage means followed by the same letter are not statistically different $($ alpha $=0.05)$

* Average damage over years, orchards and both damage check occasions

larvae could have entered the fruit before the insecticide spray. A quantitative study of $Q$. amara persistence in the field is lacking. However, the extract has been estimated to be active only over a short period of 4-6 days (Wijnen et al. 1994; Zijp and Blommers 2002a). It is, therefore, of primary importance to apply the extract during egg hatch, i.e., earlier than larval penetration McIndoo and Sievers 1917; Kienzle et al. 2002). In this study, the temperature sum application 3 days prior to peak egg hatch may have targeted a larger proportion of hatching eggs than application at the actual peak. For optimal application of insecticides with short persistency, there is a need for sufficient knowledge regarding the biology and phenology of the target insect. Adding a wetting agent can improve the effect of $Q$. amara treatment (Kienzle et al. 2006; McIndoo and Sievers 1917) but the improvement is not consistent (Paaske 2013). The results of the present study provide the possibility to use internationally proposed temperature sum constructs to create an application model for the Swedish climate. Growers unable to invest in weather stations for local temperature sum calculations could still use petal-fall to time their Q. amara application. However, in that case application should not be at $50 \%$ petal fall (BBCH 67), but at the end of observed petal fall (BBCH 69).

A $4.8-6.8 \%$ reduction in harvest results in a loss of 600-1600 euros/ha in Swedish organic production depending on the productivity of the cultivar. Furthermore, a $Q$. amara application prevents a gradual increase of the orchard population over the years. Q. amara is available both as an extract and as inexpensive wood chips for separate extraction, where the latter has been used in Sweden. Swedish growers use $Q$. amara to control both the apple sawfly and the rosy apple aphid simultaneously, which further increases its economic viability. At the moment, a formal registration process for $Q$. amara within the EU is underway.

The results from our study confirmed and clarified apple sawfly flight pattern, egg laying, and larval activity. It also showed that results from international studies on apple sawfly phenology can be used in Sweden as an effective tool to determine application timing. However, the findings should be validated with further studies in other regions and years.

Acknowledgments We thank the orchard owners, Äppelriket, students, and co-workers for their valuable contributions to the design and execution of this study. We thank Per Odén for developing and performing the Quassia amara content analysis. Without them the study would not have been possible. We also thank FORMAS, the Swedish University of Agricultural Sciences and Partnerskap Alnarp for funding the project. BR, PS, WS, MT and TT conceived and designed research. PS, WS, DN, EL, MT conducted experiments. TT, BR, PS, WS analyzed data. PS, WS, BR, TT, MT wrote the manuscript. All authors approved the manuscript.

Open Access This article is distributed under the terms of the Creative Commons Attribution License which permits any use, distribution, and reproduction in any medium, provided the original author(s) and the source are credited.

\section{References}

Agnello A, Reissig H (2010) Development and validation of a "RealTime" Apple IPM Website for New York. N Y Fruit Q 18:25-28

Ascard J, Juhlin P (2011) Växtskydd i ekologisk fruktodling, 6th edn. Svenska Jordbruksverket, Jönköping

Chaboussou F (1961) Recherohes sur l'hoplocampe du pommier (Hoplocampa testudinea Klug) methode de lutte chimique. Ann Epiphyt 12:293-315 
Ciglar I, Baric B (2002) Monitoring the appearance and possibility for prevention of the apple sawfly in Croatia. Anz Schädlingskd $75: 41-45$

Coli WM, Green TA, Hosmer TA, Prokopy RJ (1985) Use of visual traps for monitoring insect pests in the Massachusetts apple IPM program. Agric Ecosyst Environ 14:251-265

Cross JV, Solomon MG, Babandreier D, Blommers L, Easterbrook MA, Jay CN, Jenser G, Jolly RL, Kuhlmann U, Lilley R, Olivella E, Toepfer S, Vidal S (1999) Biocontrol of pests of apples and pears in northern and central Europe: 2. Parasit Biocontrol Sci Technol 9:277-314

Dicker GHL, Briggs JB (1953) Studies on Control of Apple Sawfly, Hoplocampa testudinea (Klug). I. Effect of Time of Spraying. 40th Report East Malling Research Station 1951-1952. East Malling, England, pp 151-155

Fitzmaurice GM, Laird N, Ware J (2010) Applied Longitudinal Analysis, 2nd edn. Wiley, New York

Graf B, Höhn H, Höpli HU (1996a) The apple sawfly, Hoplocampa testudinea: a temperature driven model for spring emergence of adults. Entomol Exp Appl 78:301-307

Graf B, Höpli H, Höhn H (1996b) Modelling spring emergence of the apple sawfly Hoplocampa testudinea Klug (Hymenoptera, Tenthredinidae). Acta Hort 416:263-272

Graf B, Höhn H, Höpli H (1996c) Optimizing the risk assessment for the Apple Sawfly Hoplocampa testudinea Klug (Hymenoptera, Tenthredinidae). IOBC WPRS Bull 19:113-117

Graf B, Höpli HU, Höhn H (2001) The apple sawfly, Hoplocampa testudinea: Temperature effects on adult life-span and reproduction. Entomol Exp Appl 98:377-380

Graf B, Höpli HU, Höhn H (2002) The apple sawfly, Hoplocampa testudinea: egg development and forecasting of egg hatch. Entomol Exp Appl 105:55-60

Haalboom W (1983) Observations on the apple sawfly Hoplocampa testudinea Klug with the use of visual traps. Meded Fac Landbouww Rijksuniv 48:157-161

Höhn H, Höpli H, Graf B (1993) Apple sawfly: blemishes despite control. Schweizerische Zeitschrift fur Obst- und Weinbau 129:678-684

Jaworska M (1992) Biological control of Hoplocampa testudinea Klug (Hymenoptera, Tenthreinidae). Acta Phytopathol Hun 27:311-315

Jones VP, Brunner JF, Grove GG, Petit B, Tangren GV, Jones WE (2010) A web-based decision support system to enhance IPM programs in Washington tree fruit. Pest Manag Sci 66:587-595

Kienzle J, Kopp B, Schulz C (2002) Control of the apple sawfly (Hoplocampa testudinea Klug) with extracts from Quassia amara L.: Quality and combination. In: Boos, Markus (Ed.) Ecofruit. Paper presented at 10th International Conference on Cultivation Technique and Phytopathological Problems in Organic Fruit-Growing: Proceedings to the Conference from 31st January to 2nd February 2006, Weinsberg, Germany, 2002 pp. $28-34$

Kienzle J, Zimmer J, Maxin P, Rank H, Bathon H, Zebitz CPW (2006) Control of the apple sawfly Hoplocampa testudinea Klug in organic fruit growing. In: Boos, Markus (Ed.) ecofruit - 12th International Conference on Cultivation Technique and Phytopathological Problems in Organic Fruit-Growing: Proceedings to the Conference from 31st January to 2nd February 2006 at Weinsberg, Germany, Fördergemeinschaft Ökologischer Obstbau e.V. (FÖKO), Traubenplatz 5, D-74189 Weinsberg, pp. 25-29

Kuenen DJ, Vrie M (1951) Waarnemingen over de biologie en de bestrijding van de appelzaagwesp (Hoplocampa testudinea Klug Hymenoptera, Tenthredinidae). Tijdschrift Over Plantenziekten $57: 135-157$
Manduric S (2013) Växtskyddsmedel 2013 - frukt. Svenska Jordbruksverket (SJV). http://www2.jordbruksverket.se/webdav/ files/SJV/trycksaker/Pdf_ovrigt/ovr69.pdf. Accessed 13 May 2014

McIndoo NE, Sievers AF (1917) Quassia Extract as a Contact Insecticide. J Api Res 10:497-531

Meier U, Graf H, Hack H, Hess M, Kennel W, Klose R, Mappes D, Seipp D, Stauss R, Streif J, Boom TVD (1994) Phenological growth stages of pome fruits (Malus domestica Borkh. and Pyrus communis L.), stone fruits (Prunus species), currants (Ribes species) and strawberry (Fragaria * ananassa Duch.). Nachrbl Dtsch Pflanzenschutzd 46:141-153

Miles HW (1932) On the biology of the apple sawfly, Hoplocampa testudinea Klug. Ann Appl Biol 19:420-431

Odén, P.C., Neupane, D., Moritz, T. and Rämert, B. Identification of quassin and neoquassin in aqueous extracts of Quassia amara $\mathrm{L}$ by UHPLC/ESI-LTQ-Orbitrap MS. Manuscript in preparation

Owens ED, Prokopy RJ (1978) Visual Monitoring Trap for European Apple Sawfly. J Econ Entomol 71:576-578

Paaske K (2013) Testing of plant extracts for control of apple sawfly. Trials with Quassia-MD, NeemAzal T/S and Tracer. Aarhus University, Department of Agroecology. http://orgprints.org/ 24746/7/24746.pdf. Access. 18 February 2014

Pyenson L (1943) A Destructive Apple Sawfly New to North America. J Econ Entomol 36:218-221

Roubal C, Rouzet J (2003) Development and use of a forecasting model for Cydia pomonella. Bull OEPP 33:403-405

Snyder RL (1985) Hand calculating degree days. Agr Forest Meteorol $35: 353-358$

Statsoft (2014) Statsoft version 12. http://www.statsoft.com/. Accessed 04 May 2014

Velbinger H (1939) Beitrag zur Biologie und Bekämpfung der Apfelund Birnensägewespe (Hoplocampa testudinea Klg., Hoplocampa brevis Klg.); (Hym. tenthr.). Dissertation, Friedrich Wilhelms Universität Berlin

Villalobos-Soto R, Marmillod D, Ocampo-Sánchez RA, Mora-López GA, Rojas C (1999) Variations in the quassin and neoquassin content in Quassia amara Simaroubaceae in Costa Rica: Ecological and management implications. Acta Hort 502:369-376

Vincent C, Bélair G (1992) Biocontrol of the apple sawfly, Hoplocampa testudinea, with entomogenous nematodes. Entomophaga 37:575-582

Vincent C, Mailloux M (1988) Distribution et abondance de l'hoplocampe des pommes au Québec de 1981 à 1986 (Hymenoptera: Tenthredinidae). Annls Soc ent Fr 24:39-46

Wijnen T, Bloksma J, Brouwer G (1994) Bestrijding van de appelzaagwesp (Hoplocampa testudinea, Klug) met het plantaardige middel Quassia. In. Onderzoek fruitteelt, Louis Bolk Instituut, Driebergen 39

Wildbolz T, Staub A (1986) Fang der Pflaumensägeswespen Hoplocampa minuta und $H$. flava und der Apfelsägeswepe $H$. testudinea mit weissen Fallen. - Einfluss von Temperatur, Blütezeit und Fallenposition. Mitt Schweiz Entomol Ges 59:289-298

Zijp JP, Blommers LHM (1997) Prediction of flight of apple sawfly, Hoplocampa testudinea, using temperature sums. Entomol Exp Appl 84:71-75

Zijp JP, Blommers LHM (2002a) Apple sawfly Hoplocampa testudinea (Hymenoptera, Tenthredinidae) and its parasitoid Lathrolestes ensator in Dutch apple orchards (Hymenoptera, Ichneumonidae, Ctenopelmatinae). J Appl Entomol 126:265-274

Zijp JP, Blommers LHM (2002b) Impact of the parasitoid Lathrolestes ensator (Hymenoptera, Ichneumonidae, Ctenopelmatinae) as antagonist of apple sawfly Hoplocampa testudinea (Hymenoptera, Tenthredinidae). J Appl Entomol 126:366-377 